Revista Universo Contábil, ISSN 1809-3337

FURB, v. 5, n.4, p. 44-62, out./dez., 2009

doi:10.4270/ruc. 2009430

Disponível em www.furb.br/universocontabil

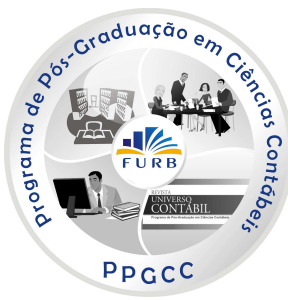

\title{
AUDITORIA INDEPENDENTE: UM ESTUDO DOS PARECERES EMITIDOS SOBRE DEMONSTRAÇÕES CONTÁBEIS DE EMPRESAS BRASILEIRAS LISTADAS NA BOVESPA E NA NYSE*
}

\section{INDEPENDENT AUDIT: A STUDY OF AUDITORS CERTIFICATES ISSUED ON FINANCIAL STATEMENTS OF BRAZILIAN COMPANIES LISTED IN BOVESPA AND NYSE}

\author{
Anderson Clivatti dos Santos \\ Graduado em Ciências Contábeis pela FURG \\ Endereço: Rua Mal. Floriano Peixoto, 296, $5^{\circ}$ andar \\ CEP: $96200-380$ - Rio Grande/RS - Brasil \\ E-mail: anderclivatti@gmail.com \\ Telefone: (53) 3293-5081
}

Marcos Antonio de Souza

Doutor em Controladoria e Contabilidade pela FEA-USP Professor do Programa de Pós-Graduação em Ciências Contábeis da Unisinos

Endereço: Av. Unisinos, 900, Cristo Rei CEP: 93022-000 - São Leopoldo/RS - Brasil

E-mail: marcosas@unisinos.br Telefone: (51) 3554-2572

Débora Gomes Machado

Mestre em Ciências Contábeis pela Unisinos Endereço: Av. Itália, Km 8, Pav. 4 - Carreiros CEP: 96201-900 - Rio Grande/RS - Brasil

E-mail: debora_furg@yahoo.com.br

Telefone: (53) 9151-3340

Rogério Piva da Silva

Doutor em Economia - AUM - Espanha Professor do Curso de Graduação em Economia da FURG Endereço: Av. Itália, Km 8, Pav. 4 - Carreiros CEP: 96201-900 - Rio Grande/RS - Brasil E-mail: dpivone @ vetorial.net Telefone: (53) 8402-1896

Artigo recebido em 23.01.2009. Revisado por pares em 23.03.2009. Reformulado em 01.05.2009. Recomendado em 12.05.2009 por Ilse Maria Beuren (Editora). Publicado em 30.11.2009. Organização responsável pelo periódico: FURB. 


\section{RESUMO}

Este estudo investiga o conteúdo dos pareceres de auditoria emitidos sobre as demonstrações contábeis de empresas brasileiras listadas na BOVESPA e na NYSE. Com essa análise procura-se identificar as principais diferenças e semelhanças no conteúdo dos pareceres emitidos sobre as demonstrações contábeis das mesmas empresas, e referentes ao mesmo período, elaboradas de acordo com os respectivos procedimentos contábeis brasileiros e norteamericanos, e apresentadas às correspondentes bolsas de valores. Trata-se de uma pesquisa descritiva e comparativa, de natureza documental, cujos dados foram coletados mediante aplicação da técnica de análise de conteúdo. Além da análise qualitativa os dados foram também submetidos a um tratamento estatístico, cuja regressão deu-se pelo uso do método ordinary least squares. As demonstrações contábeis das 26 empresas pesquisadas referem-se ao período de 2004 a 2006, redundando na análise de 156 pareceres e 709 parágrafos. Os resultados mais significativos da pesquisa indicam: a) existência de apenas um parecer com ressalva; b) os pareceres americanos dão mais destaque a eficácia dos controles internos das empresas; c) apesar de não obrigatórias na época, todas as empresas brasileiras publicaram no Brasil a DFC e a DVA; d) auditorias americanas publicam o parecer emitido por outra empresa sobre as demonstrações do ano anterior; e) as auditorias americanas enfatizam mais as divergências entre as práticas contábeis americanas e brasileiras; f) Não há diferença significativa na quantidade de parágrafos. Constata-se elevado grau de homogeneidade entre os pareceres brasileiros e americanos.

Palavras-chave: Auditoria independente. Pareceres de auditoria. Demonstrações contábeis. Princípios contábeis. Controles internos.

\section{ABSTRACT}

This study investigates the content of audit certification issued on financial statements of Brazilian companies listed in the BOVESPA and NYSE. The goal of this analysis is to identify the main differences and similarities in the certification content issued on the financial statements of the same companies, and referring to the same period, elaborated according to the respective Brazilian and North American accounting principles, and presented to the corresponding stock exchange. This is a descriptive and comparative research, having a documentary nature. The data were collected by application of content analysis technique. Besides the qualitative analysis, the data was also submitted to a statistical treatment, whose regression was done by the ordinary least squares method. The financial statements of the 26 searched companies referring to the period from 2004 to 2006, resulting in the analysis of 156 certificates and 709 paragraphs. The most significant results are: a) existence of only one opinion with exception; b) American audit certificates emphasizes more the effectiveness of the companies internal controls; c) although not compulsory at that time, all the Brazilian companies had published in Brazil the DFC and the DVA; d) American audit publish the opinion issued by another company on the financial statements of the previous year; e) the American auditors emphasize more the divergences between American and Brazilian accounting practices; f) there is no significant difference in the amount of paragraphs. Finally, there is a high homogeneity level of opinions evidenced in Brazilian and American opinions.

Keywords: Independent audit. Audit certificates. Financial statements. Accounting principles. Internal control. 


\section{INTRODUÇÃO}

O mercado acionário, nacional e internacional, vem apresentando expressiva instabilidade e momentos de turbulência, neste último ano, em face da crise econômica que se instalou no mercado de capitais de forma global. A falta de financiamentos, de credibilidade nas instituições financeiras e na recuperação da economia global tem provocado vários efeitos como a redução do volume das atividades tanto de forma local como globalizada. Os reflexos disso no mercado acionário são evidentes.

Anteriormente à crise o mercado acionário se demonstrava expressivo em relação ao crescimento no volume de negócios realizados, tornando-se uma relevante alternativa de investimento e, ao mesmo tempo, de financiamento para as empresas. A Bolsa de Valores de São Paulo (BOVESPA), juntamente com a Comissão de Valores Mobiliários (CVM), já vinham tomando iniciativas de divulgação e fortalecimento do mercado acionário, procurando torná-lo mais difundido e confiável. O intuito, de um lado, era incentivar o investidor a aplicar suas reservas nesse mercado e, de outro, estimular a abertura de capital pelas empresas. $\mathrm{Na}$ atualidade, maiores são os esforços governamentais e privados para manter o mercado acionário em alta. Não obstante, as empresas brasileiras têm também procurado negociar suas ações também em outros mercados. Dentre os existentes, o norte-americano tem sido o foco da quase totalidade dessas empresas.

São diversos os instrumentos de controle que a Lei das S/A (BRASIL, 1976) e a CVM adotam como forma de proteção ao investidor. Faz parte desses instrumentos a auditoria independente, cuja atividade tem o objetivo de emitir uma opinião acerca da adequacidade das demonstrações contábeis publicadas pelas empresas abertas. Nesse sentido, a conclusão das tarefas da auditoria se dá pela emissão do parecer sobre as demonstrações contábeis auditadas, expressando uma opinião sobre a qualidade das demonstrações contábeis. As possibilidades de opinião vão desde a ausência de qualquer ressalva até a recusa ou abstenção de opinião. $\mathrm{O}$ tipo de opinião é fruto do embasamento dado no conteúdo técnico do parecer, no qual são apresentados os principais procedimentos adotados na realização do trabalho.

Dada a globalização do mercado de capitais e o lançamento de ações em bolsas de valores do exterior, as empresas, para cumprir normas e regulamentos específicos, elaboram demonstrações contábeis com base em princípios contábeis específicos de cada país. Ao mesmo tempo, há também a obrigação de submeter tais demonstrações aos processos de auditoria dos países envolvidos. Como uma consequiência natural desse fenômeno, há diversos movimentos em direção ao desenvolvimento e harmonização de padrões de uma contabilidade internacional.

Nesse sentido, estudos direcionados a identificar e analisar diferenças de procedimentos em serviços de auditoria têm sido realizados, no âmbito de negócios globalizados. Elahee, Petrie e Ganguli (1997), por exemplo, destinaram seu estudo à comparação entre os procedimentos de auditoria adotados nos EUA e na Inglaterra.

É dessa realidade que surge a questão de pesquisa desse estudo, a saber: Quais as diferenças principais entre o conteúdo dos pareceres de auditoria independente emitidos sobre demonstrações contábeis do mesmo período elaboradas por empresas brasileiras registradas na BOVESPA e na NYSE? Implícito a tal questão de pesquisa está o objetivo geral do estudo, ou seja, identificar as diferenças entre pareceres de auditoria emitidos sobre demonstrações contábeis das mesmas empresas, porém elaboradas com base nas práticas contábeis de dois diferentes países - Brasil e EUA.

A fim de atingir o objetivo geral foram estabelecidos os seguintes objetivos específicos: a) identificar as empresas brasileiras com registro na BOVESPA e na NYSE; b) coletar as demonstrações contábeis nos sites das respectivas bolsas de valores; c) mapear as empresas de auditoria independente que auditaram as demonstrações contábeis das empresas 
no período de 2004 a 2006; d) classificar os tipos de pareceres emitidos; e) analisar e comparar o conteúdo dos pareceres.

Em função da necessária delimitação do tema, tendo em vista os objetivos estabelecidos, não faz parte deste estudo a análise específica e detalhada das normas de auditoria ou dos princípios de contabilidade geralmente aceitos no Brasil e nos EUA. Entretanto, quando pertinente, algumas colocações pontuais a esse respeito são apresentadas.

As contribuições do estudo mostram-se relevantes, caracterizadas sob dois aspectos principais. $\mathrm{O}$ primeiro, por permitir avaliar as diferentes informações disponibilizadas pelas empresas de auditoria ao mercado; $\mathrm{O}$ segundo, pela comparação que faz entre práticas e procedimentos de auditorias brasileiras e norte-americanas, oportunizando a discussão do tema no âmbito acadêmico e profissional.

\section{REFERENCIAL TEÓRICO}

\subsection{Auditoria Contábil}

Dentre os vários ramos da auditoria, a escolha para o presente estudo recaiu sobre a auditoria contábil. Attie (1998, p. 25) afirma que "a auditoria é uma especialização contábil voltada a testar a eficiência e eficácia do controle patrimonial implantado, com o objetivo de expressar uma opinião sobre determinado dado". Sá (2000) acrescenta que os exames visam apresentar opiniões, conclusões, críticas e orientações sobre as situações ou fenômenos patrimoniais, ocorridos ou por ocorrer, prospectados e diagnosticados.

A auditoria, quanto à relação existente entre o auditor e a entidade auditada, é dividida em interna e externa, esta última também denominada auditoria independente. Na auditoria interna, realizada por funcionário da própria entidade auditada, é dado ênfase aos controles internos, averiguando se as normas internas estão sendo adotadas, analisando a necessidade de novas normas ou o aprimoramento das existentes. Já na auditoria independente, realizada por profissional não vinculado à empresa, apesar dos controles internos também terem sua eficácia avaliada, o foco principal são as demonstrações contábeis, especificamente se elas refletem a real situação patrimonial e financeira da auditada.

\subsection{Auditoria Independente}

A auditoria independente realiza todo um trabalho de averiguação da adequacidade, tempestividade e conformidade dos dados apresentados nas demonstrações contábeis, tendo como balizador principal os princípios fundamentais de contabilidade. O intuito principal é validar as informações divulgadas através daquelas demonstrações. Isso está colocado de forma explícita por Franco e Marra (2000) quando afirmam que o fim principal da auditoria é a confirmação dos registros contábeis e conseqüentes demonstrações contábeis, avaliando a adequação dos registros. Assim, em termos amplos, o objetivo final é dar à administração, ao fisco, aos proprietários e financiadores do patrimônio a convicção de que as demonstrações contábeis refletem, ou não, a situação do patrimônio em determinada data e suas variações em certo período.

O Conselho Federal de Contabilidade (CFC), através da Norma Brasileira de Contabilidade $\mathrm{n}^{\circ}$. 11 (NBC T 11.1.1.1), determina que a auditoria das demonstrações contábeis "constitui o conjunto de procedimentos técnicos que tem por objetivo a emissão de parecer sobre a sua adequação, consoante os Princípios Fundamentais de Contabilidade e as Normas Brasileiras de Contabilidade e, no que for pertinente, a legislação específica". As demonstrações contábeis, sobre as quais os auditores emitem parecer, na época da pesquisa, compreendiam o Balanço Patrimonial (BP), a Demonstração do Resultado do Exercício (DRE), a Demonstração das Mutações do Patrimônio Líquido (DMPL), a Demonstração das 
Origens e Aplicações de Recursos (DOAR) e as Notas Explicativas (NE). Em razão da alteração trazida pela Lei $n^{\circ}$. 11.638/07 (BRASIL, 2007), no lugar da DOAR passou a ser obrigatória a elaboração, bem como objeto de parecer do auditor, da Demonstração do Fluxo de Caixa (DFC). Além da DFC também passou a ser de emissão obrigatória a Demonstração do Valor Adicionado (DVA).

Esse parecer, uma manifestação de opinião, é fundamentado nas evidências e provas que o auditor reúne ao longo da execução dos trabalhos, as quais são obtidas através dos procedimentos de auditoria, definidos como "um conjunto de técnicas que o auditor utiliza para colher as evidências sobre as informações das demonstrações financeiras" (ALMEIDA, 2003, p. 55).

$\mathrm{O}$ CFC, por meio da NBC $\mathrm{T} 11$, estabelece que os procedimentos de auditoria abrangem testes de observância e testes substantivos. Sintetizando as idéias de Antunes (1998; 2004) e de Almeida (2003), entende-se que o auditor, na realização de seu trabalho, reúne fatos, provas, formulários, questionários, cópias de documentos, realiza anotações e observações que servirão de base para a opinião que irá emitir sobre as demonstrações contábeis da empresa. Pela NBC T 11.3.1.3, o CFC enfatiza que:

\footnotetext{
os papéis de trabalho constituem a documentação preparada pelo auditor ou fornecida a este na execução da auditoria. Eles integram um processo organizado de registro de evidências da auditoria, por intermédio de informações em papel, meios eletrônicos ou outros que assegurem o objetivo a que se destinam.
}

Ainda de acordo com a NBC T 11.4.1.3, quando do planejamento dos trabalhos há necessidade de um estudo prévio da empresa a ser auditada e do mercado em que ela está inserida, além da necessidade de o auditor possuir conhecimentos relevantes sobre esse mercado. Tais situações podem exigir a realização dos trabalhos em parceria com outros profissionais da empresa de auditoria. Por exemplo, a auditoria numa empresa industrial que realiza rotineiras exportações e importações de commodities, o auditor, caso não tenha sólidos conhecimentos aduaneiros, pode necessitar do auxílio de um parceiro que o tenha.

Também é do planejamento que advém o programa de auditoria, documento que contém os procedimentos mais adequados para serem utilizados visando alcançar o resultado almejado. O programa de auditoria deve ser escrito e possuir um detalhamento capaz de auxiliar a sua execução, deixando claro o que o auditor deve examinar o sistema contábil e o dos controles internos da empresa auditada (CFC - NBC T 11.4). Franco e Marra (2000) mencionam que o programa deve ser amplo e flexível para que possa ser reajustado no decorrer de sua execução e deve ser baseado nos objetivos gerais a que se destina e, em particular, na avaliação dos controles internos da empresa auditada. Os autores acrescentam que e recomendável, no planejamento, preparar programas distintos às diversas áreas da empresa auditada, visando realizar o trabalho de forma concomitante em todas elas.

\subsection{Parecer de Auditoria}

Araújo (2003, p. 71) destaca a importância desta peça contábil ao afirmar que "o parecer do auditor independente desempenha uma função da maior relevância no cenário empresarial, em virtude de assegurar a lisura dos informes contábeis".

A opinião do auditor, exposta via parecer, sintetiza o conceito por ele formado acerca das demonstrações contábeis publicadas. Se o auditor detectar a ocorrência de eventos subseqüentes relevantes, na realização do trabalho, deve considerar no seu parecer os respectivos efeitos, "mencionando-os como ressalva ou em parágrafo de ênfase, quando não ajustadas ou reveladas adequadamente" (NBC T 11.16.1.2). Salienta-se que o CFC, 
consistente com o estabelecido na norma NBC T 11.16, considera como evento subseqüente, o ocorrido entre as datas do balanço e do parecer do auditor.

Por meio da NBC T 11.3 o CFC determina as características que o parecer deve obedecer. Franco e Marra (2000) ressaltam que o parecer do auditor deve esclarecer: a) a que ele se destina; b) que a administração da auditada é responsável pela elaboração das demonstrações contábeis objeto da auditoria; c) a responsabilidade do auditor no trabalho executado; d) quais os procedimentos de auditoria que foram utilizados no decorrer do trabalho.

Almeida (2003) destaca que as demonstrações contábeis apresentam também os valores do ano imediatamente anterior, o auditor deve emitir parecer abrangendo os dois exercícios sociais. No caso de outro auditor ter sido o responsável pelo parecer das demonstrações do ano anterior, este fato deve ser mencionado no parecer atual.

\subsection{Tipos de Parecer}

Os pareceres podem ser classificados, de acordo com a natureza da opinião que contém, em: sem ressalva; com ressalva; adverso; com abstenção de opinião.

O parecer sem ressalva é o parecer padrão, também conhecido como "parecer limpo". Ele é conciso, mencionando somente o indispensável, conforme determinado pelas normas de auditoria. Quando emitido, o auditor manisfesta seu entendimento sobre o fato de não haver aspectos relevantes que afetem as demonstrações contábeis elaboradas. Dutra, Alberto e Van Bellen (2007, p. 4) afirmam que "o parecer sem ressalva implica em afirmar que, em tendo havido alterações na observância das práticas contábeis, elas tiveram seus efeitos avaliados e aceitos, e estão devidamente revelados nas demonstrações contábeis".

O parecer sem ressalva, de acordo com o modelo apresentado na seção 11.3.2.3 da norma CFC NBC T 11, deve conter três parágrafos. No primeiro, há a responsabilidade do auditor e a menção a que ele se propõe, o segundo esclarece a abrangência da auditoria e como ela foi executada. No terceiro parágrafo é expressa a opinião do auditor acerca do trabalho concluído.

A NBC T 11.3.3 traz as situações que impedem a emissão do parecer sem ressalva. Quando o auditor emitir qualquer parecer que não seja o sem ressalva, ele deve incluir, num parágrafo específico e anterior ao da opinião, as razões que o levaram a emitir tal parecer e, se viável, a identificação das conseqüências que estas razões podem ter sobre as demonstrações contábeis. Podem ocorrer, conforme previsto na NBC T 11.3.7, incertezas quanto a possíveis fatos relevantes. Neste caso, se o desfecho for improvável e houver informações suficientes a respeito nas demonstrações contábeis, o auditor deve acrescentar um parágrafo de ênfase, após o parágrafo de opinião, referenciando o fato, e emitir um parecer sem ressalva. Senão, seu parecer deverá ser com ressalva ou de opinião adversa.

Dutra, Alberto e Van Bellen (2007) salientam que um parágrafo de ênfase tem a possibilidade de conter informações mais significativas do que algumas ressalvas, pois tratase de uma incerteza do auditor, enquanto que nas ressalvas os fatos relacionados são esclarecidos e mensurados. Almeida (2003) acrescenta que, neste caso, é preciso deixar claro o efeito sobre: a) a situação patrimonial e financeira; b) o resultado das operações; c) as mutações do patrimônio líquido e das origens e aplicações de recursos. O CFC, pela NBC T 11.3, determina que o parecer com ressalva deve seguir o modelo do parecer sem ressalva, com a inclusão do termo "exceto por", "exceto quanto" ou "com exceção de", o qual deve aludir o assunto objeto da ressalva.

Quando as demonstrações contábeis não expressam corretamente a situação patrimonial e financeira, os resultados do exercício e as alterações no capital circulante da empresa, em consonância com os princípios fundamentais de contabilidade, deve ser emitido 
o parecer adverso, conforme advogam Franco e Marra (2000). Segundo a norma CFC NBC T 11.3.5, deve prevalecer o parecer adverso quando as incorreções detectadas nas demonstrações contábeis são de uma amplitude que impossibilita a emissão do parecer com ressalva.

Quando o auditor, na realização do trabalho de auditoria, não obtém certeza capaz de abalizar sua opinião quanto às demonstrações contábeis tomadas em conjunto, deve emitir o parecer com abstenção de opinião, indicando, em parágrafo intermediário próprio, as razões da negativa de opinião. Mesmo não havendo uma opinião expressa do auditor acerca das demonstrações contábeis, este não está isento da responsabilidade de divulgar, via parecer, qualquer incorreção relevante que tenha tomado conhecimento durante a realização do trabalho de auditoria e que possa interferir nos valores das demonstrações contábeis, conforme o disposto na NBC T 11.3.6.

De acordo com Franco e Marra (2000, p.557), a abstenção de opinião "geralmente é adequada quando o auditor não teve condições de realizar um exame que compreendesse o alcance necessário para que ele pudesse reunir os elementos de juízo suficientes para permitirlhe formar uma opinião sobre as demonstrações contábeis objeto de seu exame". Viu-se que as situações de utilização de cada tipo de parecer são bem claras e distintas, não devendo haver margem de dúvida no emprego de um ou de outro, pelo auditor.

\subsection{Aspectos Gerais da Auditoria Adotada nos EUA}

Dados os objetivos estabelecidos, neste estudo são consideradas as práticas contábeis adotadas nos EUA, estabelecidas pelo Financial Accounting Standards Board (FASB) (2007) e as normas de auditoria, estabelecidas pelos Statements on Auditing Standards (SAS).

Nos EUA, os procedimentos e padrões de auditoria independente foram tradicionalmente estabelecidos pelo Auditing Standards Board (ASB), o que tem ocorrido por meio da emissão dos SAS. Conforme apresentado por AICPA (2009), o ASB foi constituído em 1978 como órgão de autoridade máxima para estabelecer os procedimentos de auditoria geralmente aceitos (GAAS). Observa-se que cada vez mais há sincronia entre essas normas e aquelas estabelecidas em nível internacional (IFAC, 1997).

Mais recentemente os padrões e procedimentos de auditoria nos EUA foram influenciados pela Sarbanes-Oxley Act of 2002, que alterou a hierarquia dos procedimentos de auditoria geralmente aceitos. A legislação estabeleceu que um novo órgão, o Public Company Accounting Oversight Board (PCAOB) e a Securities Exchange Commission (SEC) passariam a ter autoridade final a respeito da regulação sobre a atividade de auditoria, envolvendo os padrões da atuação dos contadores e das empresas que prestam serviços de auditoria para as empresas abertas (public companies). As empresas de auditoria e os contadores públicos passaram a ter registro no PCAOB e seguem todos os padrões, princípios, regras e interpretações por ele emitidos. O PCAOB adotou em 2003, temporariamente, como suas regras de auditoria, os padrões estabelecidos pelo ASB. Tem-se, então, que o PCAOB foi criado para proteger os investidores e os interesses públicos, o que se dá pela emissão de corretos e transparentes relatórios de auditoria independente (PCAOB, 2009)..

De acordo com o PCAOB (2009), e conforme prescrito na SAS $\mathrm{n}^{\circ} 1$, o objetivo primário da auditoria independente das demonstrações contábeis é expressar uma opinião acerca da adequacidade dessas demonstrações, elaboradas de acordo com as práticas contábeis aceitas pelos USGAAP, em todos seus aspectos relevantes.

Pesquisa realizada sobre os aspectos e procedimentos fundamentais da auditoria independente não identifica diferenças significativas entre o que está regulamentado nas duas esferas de abrangência do estudo, Brasil e EUA. Essa constatação pode ser verificada em 
algumas das obras pesquisadas, tais como: Roussey (1996); Almeida (2002); Dixon, Mousa e Woodhead (2004); IAASB (2004); Smith, Sagafi-Najad e Wang (2008).

Não obstante essas similaridades, outros estudos recentes nos EUA sobre procedimentos de auditoria tem tratado de aspectos específicos e que merecem destaque. Davis (2004) faz uma interessante abordagem sobre o necessário discernimento para identificar as diferenças não tão claras sobre os tipos de pareceres. Ele desenvolve seu estudo no contexto do uso de pareceres com abstenção de opinião.

Whittington et al. (2006) destacam as mudanças determinadas pela SAS 103 de dez/2005, em relação a SAS 96 de jan/2002, referentes a elaboração e uso dos papéis de trabalho utilizados pelo auditor para materializar as evidencias obtidas no desenvolvimento da auditoria, base para conclusões e emissão de parecer.

O estudo de Weinstein (2007) trata de outro tradicional procedimento de auditoria, ou seja, das estimativas e julgamentos efetuados pelo auditor para avaliar a evidência e determinar a materialidade das informações abrangidas ou não pelos trabalhos. Ao destacar as dificuldades de mensurar os fatores qualitativos da materialidade Weinstein destaca o possível uso possível das técnicas da fuzzy logic.

Church, Davis e McCracken (2008) discutem a estrutura e conteúdo dos pareceres de auditoria, por meio dos quais a opinião é emitida e tornada pública. A discussão qualitativa desses aspectos pelos autores parte das críticas que são direcionadas ao auditor em função das falhas em identificar os casos nos quais as demonstrações contábeis não são elaboradas em conformidade com os princípios contábeis geralmente aceitos (USGAAP).

Por fim, tem-se o estudo de Wortmann (2009), o qual retoma a questão do uso da amostragem nos testes de auditoria. Ao destacar os principais erros cometidos na quantificação e uso da amostragem, Wortmann remete ao conteúdo da revisão da norma SAS 39, revisada pela norma SAS 111, a qual clarifica, inclusive, os procedimentos derivados do uso de técnicas estatísticas.

\section{ASPECTOS METODOLÓGICOS}

Este estudo foi desenvolvido buscando-se identificar as diferenças fundamentais no conteúdo de pareceres de auditoria emitidos por auditorias norte-americanas e auditorias brasileiras.

O estudo, quanto aos seus objetivos, e segundo Marconi e Lakatos (2006), classificase como pesquisa exploratória e descritiva. Quanto aos métodos de procedimento, classificase como pesquisa documental. De acordo com Gil (2002), a pesquisa documental vale-se de materiais que ainda não receberam nenhum tratamento analítico. Neste caso foram analisados 175 pareceres de auditoria, relativos aos exercícios de 2004, 2005 e 2006, de 26 companhias abertas brasileiras, disponibilizados nos portais da Bovespa (2007) e da Nyse (2007).

Quanto à forma de abordagem do problema, trata-se de uma pesquisa com características quantitativa e qualitativa. Raupp e Beuren (2004) ressaltam que em contabilidade é bastante usual a pesquisa qualitativa, pois a contabilidade apesar de lidar intensamente com números, é uma ciência social e não exata. Segundo Gil (2002), é preciso levar em conta no momento da classificação do estudo a natureza dos dados coletados, a extensão da amostra e os instrumentos de pesquisa.

Para coleta de dados foi utilizada a técnica de análise de conteúdo dos pareceres de auditoria. A população pesquisada envolve as companhias abertas brasileiras com registro na Bolsa de Valores de São Paulo (BOVESPA) e na Bolsa de Valores de Nova York (NYSE). As empresas registradas na NYSE divulgam suas demonstrações contábeis, elaboradas de acordo com as práticas contábeis norte-americanas (USGAAP), e o respectivo parecer da 
auditoria independente, além de outras informações relevantes, no relatório 20-F, um dos relatórios exigidos pela Securities and Exchange Commission (SEC).

A amostra inicial deste estudo se constituiu de 38 registros de empresas brasileiras listadas na NYSE e na BOVESPA em outubro de 2007. Dessa amostra, foram excluídas as seguintes empresas: a) Cia de Bebidas das Américas, Cia Energética de Minas Gerais, Petróleo Brasileiro S/A, e a Telecomunicações Brasileiras S/A. Nesses casos, as empresas foram excluídas por possuírem dois registros, sendo um relativo às ações preferenciais e outro às ordinárias. Assim, não há demonstrações contábeis e pareceres de auditoria distintos; b) Cosan Limited e a Gafisa S.A, por terem iniciado a oferta pública de ações na NYSE em 2007; c) Telecomunicações Brasileiras S/A, por se encontrar em processo de descontinuidade de suas atividades; d) Cia Vale do Rio Doce, Empresa Brasileira de Aeronáutica, TAM S/A e União de Bancos Brasileiros S/A, por não terem ofertado ações nas duas bolsas de valores, concomitantemente, no período estudado.

Sendo assim, a amostra final constituiu-se de 26 empresas brasileiras com registros simultâneos na NYSE e na BOVESPA, apresentadas no Quadro 1.

\begin{tabular}{|l|c|}
\hline \multicolumn{1}{|c|}{ Nome Empresa } & Siglas \\
\hline Ambev - Companhia de Bebidas das Americas & ABV \\
\hline Aracruz Celulose S.A. & ARA \\
\hline Banco Bradesco S.A. & BBD \\
\hline Banco Itau Holding Financeira S.A & ITU \\
\hline Brasil Telecom Participações S.A. & BRP \\
\hline Brasil Telecom S.A. & BTM \\
\hline Braskem S.A. & BAK \\
\hline Companhia Brasileira de Distribuição & CBD \\
\hline Companhia Energética de Minas Gerais - CEMIG & CIG \\
\hline Companhia Paranaense de Energia (COPEL) & ELP \\
\hline Companhia Siderúrgica Nacional & SID \\
\hline CPFL Energia S.A. & CPL \\
\hline Gerdau S.A. & GGB \\
\hline Gol Linhas Aéreas Inteligentes S.A. & GOL \\
\hline Perdigão S.A. & PDA \\
\hline Petrobras - Petróleo Brasileiro S.A. & PBR \\
\hline SABESP & SBS \\
\hline Sadia S.A. & SDA \\
\hline Tele Norte Celular Participações S.A. & TCN \\
\hline Tele Norte Leste Participacoes S.A. & TNE \\
\hline Telecomunicaçôes de Sao Paulo S/A-Telesp & TSP \\
\hline Telemig Celular Participações S.A. & TMB \\
\hline Tim Participações S.A. & TSU \\
\hline Ultrapar Participacoes S.A. & UGP \\
\hline Vivo Participações S.A. & VIV \\
\hline Votorantim Celulose e Papel S.A. & VCP \\
\hline Quadro1 - Empresas pesqusada & \\
\hline
\end{tabular}

\section{Quadro 1 - Empresas pesquisadas}

Fonte: NYSE e BOVESPA (2007).

Dos pareceres estudados foi trabalhado o conteúdo de 709 parágrafos. Primeiramente, eles foram analisados e interpretados para, posteriormente, serem categorizados. As categorias foram estruturadas de acordo com a necessidade de sintetizar o conteúdo de cada parágrafo analisado, de modo a permitir a padronização das informações, possibilitando, assim, a 
quantificação e sintetização dos dados para interpretação e análise dos resultados. As 26 empresas da amostra final apresentaram 156 pareceres de auditoria independente nos três exercícios sociais pesquisados (2004 a 2006).

A técnica utilizada para análise dos dados foi análise de conteúdo que, segundo Martins (2002), busca descrever ou interpretar o conteúdo das mensagens. Gil (2002) salienta que o aparecimento da referida técnica foi determinado pela necessidade de interpretação do grande volume de materiais produzidos pelos meios de comunicação. Silva (2003) afirma que essa técnica não se propõe a substituir a análise formal estatística, mas descobrir nuances nas entrelinhas mais subjetivas do objeto, tendo em vista que a padronização das análises formais dificulta essa descoberta.

Também foi realizada uma simulação por regressão, dos dados apurados no trabalho. O método de regressão utilizado foi o Ordinary Least Squares - mínimos quadrados ordinários -, que de acordo com Hill, Griffiths e Judge (2003), e Wooldridge (2006), se configura em uma das técnicas mais praticadas para análises de regressão limitadas por situações especiais. Ao realizar esta simulação, levou-se em conta o ingresso de empresas brasileiras no mercado acionário americano, desconsiderando outros efeitos de caráter político e econômico relacionados às crises de mercado. Para operacionalizar os cálculos da regressão, utilizou-se o software econométrico Eviews. A apresentação e analise dos dados estão sintetizadas na seção seguinte.

\section{APRESENTAÇÃO E ANÁLISE DOS DADOS}

\subsection{Empresas de Auditoria}

Os trabalhos de auditoria realizados sobre as demonstrações contábeis divulgadas no mercado brasileiro, no período analisado, estão majoritariamente concentrados em seis empresas de auditoria. Dentre essas, estão quatro grandes empresas mundiais de auditoria, as quais auditaram as demonstrações de empresas registradas em ambas as bolsas de valores (Quadro 2).

\begin{tabular}{|l|l|}
\hline \multicolumn{2}{|c|}{ Empresas de Auditoria } \\
\hline Deloitte Touche Tohmatsu & KPMG Auditores Independentes \\
Directa Auditores & PricewaterhouseCooppers \\
Ernst \& Young Auditores Independentes & BDO Trevisan Auditores Independentes \\
\hline
\end{tabular}

Quadro 2 - Empresas de Auditoria

As empresas listadas no Quadro 2 atuaram em todo o período analisado. Entretanto, as empresas brasileiras BDO Trevisan e Directa Auditores atuaram somente nas empresas registradas na BOVESPA.

Apesar dessa concentração em apenas seis empresas, há de se salientar que, conforme banco de dados da CVM (2007), em outubro de 2007 havia 93 auditores pessoa física e 332 auditores pessoa jurídica habilitados, no Brasil, a realizar o trabalho de auditoria independente em demonstrações contábeis. Assim, nas 26 empresas listadas na BOVESPA, apenas 6 auditores, dos 425 possíveis, realizaram todo o trabalho no período. A atuação das empresas de auditoria na amostra da pesquisa está apresentada na Tabela 1. 
Tabela 1 - Atuação das Empresas de Auditoria - BOVESPA

\begin{tabular}{c|cc|cc|cc|cc}
\hline Empresas de & \multicolumn{2}{|c|}{2004} & \multicolumn{2}{c|}{2005} & \multicolumn{2}{c|}{2006} & \multicolumn{2}{c}{ Média } \\
\cline { 2 - 9 } Auditoria & Freq & $\%$ & Freq & $\%$ & Freq & $\%$ & Freq & $\%$ \\
\hline Deloitte & 9 & 35 & 8 & 31 & 13 & 50 & 10 & 38 \\
KPMG & 4 & 15 & 4 & 15 & 2 & 8 & 3 & 12 \\
Pricewaterhouse & 7 & 27 & 7 & 27 & 5 & 19 & 6 & 23 \\
Ernst \& Young & 5 & 19 & 6 & 23 & 4 & 15 & 5 & 19 \\
BDO Trevisan & 1 & 4 & 1 & 4 & 1 & 4 & 1 & 4 \\
Directa & 0 & 0 & 0 & 0 & 1 & 4 & 1 & 4 \\
\hline Total & 26 & 100 & 26 & 100 & 26 & 100 & 26 & 100 \\
\hline
\end{tabular}

Observa-se, pelos dados da Tabela 1, que na média dos trabalhos de auditoria realizados no período pesquisado (2004 a 2006), houve a predominância da Deloitte (38\%), seguida da Pricewaterhouse (23\%), da Ernst \& Young (19\%) e da KPMG (12\%). As brasileiras BDO Trevisam e Directa estão representadas com inexpressivos $4 \%$.

A Tabela 2 retrata os dados referentes à participação das empresas de auditoria na realização dos trabalhos prestados às empresas brasileiras que desenvolveram demonstrações contábeis de acordo com os padrões norte-americanos, apresentadas na NYSE.

Tabela 2 - Atuação das Empresas de Auditoria - NYSE

\begin{tabular}{c|cc|cc|cc|cc}
\hline \multirow{2}{*}{$\begin{array}{c}\text { Empresas de } \\
\text { Auditoria }\end{array}$} & \multicolumn{2}{|c|}{2004} & \multicolumn{2}{c|}{2005} & \multicolumn{2}{c|}{2006} & \multicolumn{2}{c}{ Média } \\
\cline { 2 - 9 } & Freq & $\%$ & Freq & $\%$ & Freq & $\%$ & Freq & $\%$ \\
\hline Deloitte & 9 & 35 & 8 & 31 & 13 & 50 & 10 & 38 \\
KPMG & 3 & 11 & 3 & 11 & 2 & 8 & 3 & 10 \\
Pricewaterhouse & 9 & 35 & 9 & 35 & 6 & 23 & 8 & 31 \\
Ernst \& Young & 5 & 19 & 6 & 23 & 5 & 19 & 5 & 21 \\
BDO Trevisan & 0 & 0 & 0 & 0 & 0 & 0 & 0 & 0 \\
Directa & 0 & 0 & 0 & 0 & 0 & 0 & 0 & 0 \\
\hline Total & 26 & 100 & 26 & 100 & 26 & 100 & 26 & 100 \\
\hline
\end{tabular}

Em termos gerais, não se observam diferenças significativas daqueles dados apresentados na Tabela 1, referentes às auditorias das demonstrações contábeis elaboradas no Brasil. Isso indica a existência de contratos globais de auditoria, justificando a nula participação das auditorias brasileiras no exterior.

Provavelmente também haja o interesse das empresas auditadas em utilizar as empresas de auditorias com mais tradição no mercado mundial, as quais podem, talvez, transmitir maior segurança e atratividade ao investidor atuante na bolsa norte-americana.

A análise da evolução anual das participações revela um avanço da Deloitte, aumentando de nove para treze clientes, contrariamente à Pricewaterhouse que reduziu de nove para seis. Nas duas demais empresas de auditoria, constata-se a redução da KPMG (de três para dois clientes) e a manutenção da Ernst \& Young com cinco clientes. Essa estrutura de participação, em seu aspecto geral de domínio da Deloitte e da Pricewaterhouse em segundo lugar, é a mesma retratada no mercado brasileiro (Tabela 1).

Na Figura 1, é evidenciada a participação global das empresas de auditoria em relação à quantidade total dos pareceres analisados, ou seja, das demonstrações contábeis brasileiras e norte-americanas. 


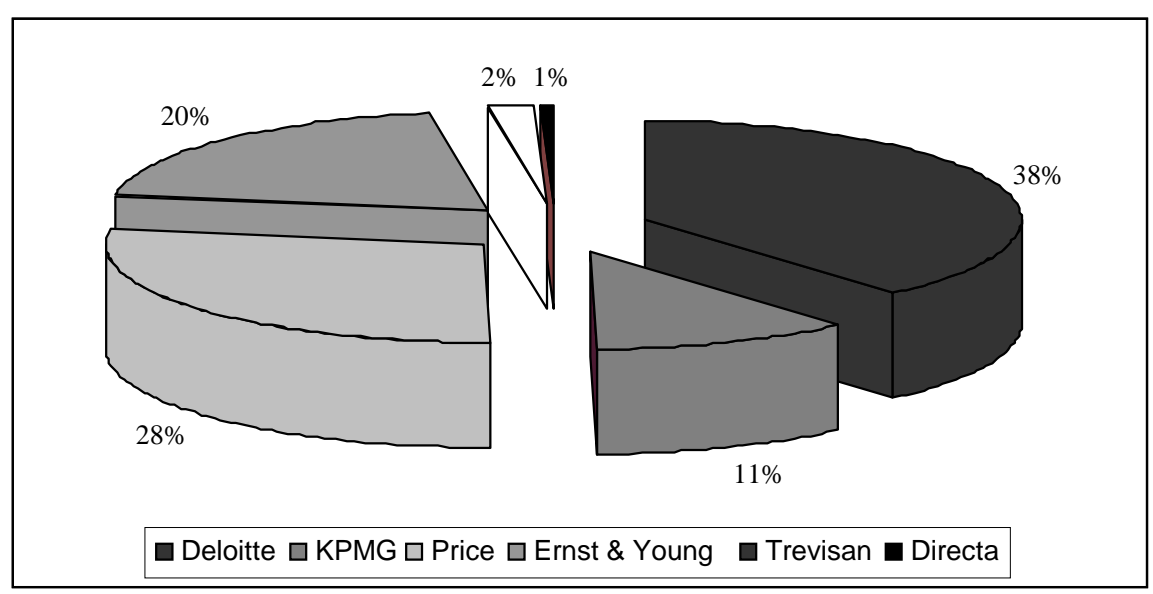

Figura 1 - Empresas de Auditoria que atuaram na Nyse e Bovespa

Os dados da Figura 1 foram obtidos através do resultado da análise do percentual de clientes que cada empresa de auditoria teve no período para a elaboração do parecer de auditoria, com relação às empresas brasileiras que negociam ações na BOVESPA e na NYSE. Dentre os 156 pareceres analisados, a empresa Deloitte se destaca como a mais atuante, responsável pela emissão de 60 pareceres (equivalente a 38\% do total); a Pricewaterhouse com 43 pareceres (28\%); a Ernst \& Young com 31 pareceres (20\%); a KPMG com 18 pareceres $(11 \%)$. Dentre as auditorias brasileiras, têm-se a BDO Trevisan com 3 pareceres $(2 \%)$ e a Directa com apenas 1 parecer $(1 \%)$.

Tomando-se como base a amostra pesquisada, foi observado que esse nicho de mercado está concentrado nas quatro grandes empresas mundiais. Tal fato pode estar alicerçado na questão de que as empresas, por possuírem ações negociadas na Bolsa de Valores de Nova York, necessitem contratar os serviços de auditoria independente daquelas empresas habilitadas pelos órgãos reguladores do mercado acionário norte-americano.

Constata-se, também, que em apenas três das 26 empresas estudadas não há coincidência da mesma empresa de auditoria no exame das demonstrações. Ou seja, em 88,5\% dos casos, tanto as demonstrações contábeis apresentadas à BOVESPA como aquelas submetidas à NYSE, foram examinadas pela mesma empresa de auditoria. A Tim Participações S.A. apresentou apenas o exercício de 2006 com auditor responsável diferente; no Banco Bradesco S.A., esse fato ocorreu em 2004 e 2005, e na empresa Tele Norte Celular Participações S.A. essa ocorrência é referida nos três exercícios os 3 exercícios pesquisados.

Como já exposto, existem indícios para a inferência de que as empresas brasileiras que participam do mercado acionário no exterior buscam empresas de auditoria conceituadas internacionalmente, visando oferecer maior credibilidade e obter maior confiabilidade quanto à correção dos resultados apresentados.

Como forma de testar essa tendência, aplicou-se um método econométrico para a análise dos dados. Primeiramente, obteve-se o coeficiente de correlação que permite analisar a existência de relação linear entre as variáveis analisadas (Tabela 3).

Tabela 3 - Coeficiente de Correlação entre Empresas Auditadas e Empresas Internacionais de Auditoria

\begin{tabular}{l|c|c}
\hline & Empresas Brasileiras & Auditoria Internacional \\
\hline Empresas Brasileiras & 1.000000 & 0.967868 \\
\hline Auditoria Internacional & 0.967868 & 1.000000 \\
\hline
\end{tabular}

Conforme dados da Tabela 3, há relação positiva entre o ingresso de empresas brasileiras na NYSE e a utilização de auditorias internacionais para realização de seus relatórios, inclusive para o mercado brasileiro. A partir deste resultado, realizou-se a regressão 
por mínimos quadrados ordinários. Nesse caso, a variável explicada são as empresas de auditoria internacional e a variável explicativa é representada pelas empresas brasileiras que ingressam no mercado acionário norte-americano.

Os resultados estão apresentados na Tabela 4. Constata-se existir uma probabilidade superior a $94 \%$ de que o ingresso de empresas brasileiras na NYSE tenha influência na escolha de empresas de auditoria internacional. $\mathrm{O}$ teste $\mathrm{F}$ mostra que a regressão existe com $94,21 \%$ de confiança.

O valor do parâmetro estatístico $\mathrm{R}^{2}$, com um ajuste de $99 \%$, acentua a concordância entre os dados. A pesquisa tem um universo de tempo bastante reduzido, 2004 a 2006. Entretanto, conforme investigação adicional, ficou evidenciado, com dados de anos anteriores a 2004, que eles pouco contribuíram para modificar os resultados apresentados na regressão apresentada na Tabela 4.

Tabela 4 - Regressão por Mínimos Quadrados Ordinários

\begin{tabular}{lcccc}
\hline $\begin{array}{l}\text { Dependent Variable: AUDITORIA INTERNACIONAL } \\
\text { Method: Least Squares } \\
\text { Date: 03/24/08 Time: } 16: 28\end{array}$ & & & \\
$\begin{array}{l}\text { Sample: 2004 2006 } \\
\text { Included observations: } 3\end{array} \quad$ Coefficient & Std. Error & t-Statístic & Prob. \\
$\quad$ Variable & -20.46154 & 4.199183 & -4.872743 & 0.1289 \\
$\quad$ C & 1.461538 & 0.133235 & 10.96966 & 0.0579 \\
EMPRESAS BRASILEIRAS & 0.991758 & F-statistic & & 120.3333 \\
R-Squared & 2.8461538 & Prob(F-statístic) & & 0.057875 \\
Durbin-Watson stat & & & & \\
\hline
\end{tabular}

\subsection{Características do Parecer de Auditoria}

Os 156 pareceres de auditoria estavam formados por 709 parágrafos e corresponderam ao objeto da análise de conteúdo. Nos 78 pareceres das demonstrações apresentadas à BOVESPA, constatou-se a existência de 368 parágrafos, em contrapartida aos 341 dos 78 pareceres emitidos sobre as demonstrações submetidas à NYSE. Nota-se que, além dos pareceres norte-americanos conterem menos parágrafos (-7,3\%), também expuseram parágrafos (num total de seis) com a descrição de mais de uma categoria, sintetizando várias categorias no mesmo parágrafo. A amostra estudada apresentou 13 categorias, surgindo, desse fato, a frequiência de 721 representações nas 33 categorias identificadas. A análise de conteúdo buscou interpretar cada parágrafo e descrever sinteticamente o conteúdo apresentado. O resultado está apresentado na Tabela 5.

Conforme exposto na Tabela 5, e de acordo com a descrição nas normas brasileiras editadas pelo $\mathrm{CFC}$, representadas pelas categorias 1,2 e 3, os pareceres brasileiros de auditoria, divulgados na BOVESPA, possuem essas categorias presentes em praticamente todos os pareceres emitidos. De fato, dos 368 parágrafos escritos, 233 (equivalente a $63 \%$ do total) continham o padrão brasileiro. Isso indica que os pareceres apresentados à BOVESPA seguem a legislação pertinente. Do restante, 62 parágrafos (próximo a $17 \%$ da amostra) são relativos às demonstrações suplementares. Os demais 73 parágrafos, ou 20\% do total, estão pulverizados nas categorias de esclarecimentos.

Ainda com base nos dados da Tabela 5, e com relação aos pareceres das demonstrações apresentadas à NYSE, nota-se que as categorias 1, 2 e 3 caem para 58\% do 
total. Já com relação às demonstrações suplementares, constata-se redução de 5\%. Essa ocorrência pode ser consequiência do fato de as demonstrações serem suplementares no Brasil mas obrigatórias nos Estados Unidos.

Outra categoria destacada é com relação aos pareceres norte-americanos procurarem esclarecer, em parágrafo específico (31 parágrafos na amostra analisada), que há divergências entre as normas brasileiras e norte-americanas. Por fim, destaca-se a categoria referente aos controles internos (66 parágrafos, equivalente a 19\% do total), principalmente pelos esclarecimentos dados às suas características e limitações, assim como a opinião do auditor sobre a qualidade geral deles.

\section{Tabela 5 - Categorias e Frequências dos Pareceres}

\begin{tabular}{|c|c|c|c|c|c|c|c|}
\hline \multicolumn{2}{|r|}{ Categorias } & \multicolumn{2}{|c|}{ BOVESPA } & \multicolumn{2}{|c|}{ NYSE } & \multicolumn{2}{|c|}{ Total } \\
\hline Ord & Discriminação & Freq & $\%$ & Freq & $\%$ & Freq & $\%$ \\
\hline 1 & Responsabilidade do auditor e menção a que ele se propõe & 77 & 21 & 67 & 19 & 144 & 20 \\
\hline 2 & Abrangência da auditoria e como foi executada & 78 & 21 & 60 & 17 & 138 & 19 \\
\hline 3 & Opinião do auditor acerca do trabalho executado & 78 & 21 & 76 & 22 & 154 & 21 \\
\hline 4 & Esclarecimentos sobre pareceres de outros auditores & 19 & 5 & 0 & 0 & 19 & 3 \\
\hline 5 & Esclarecimentos sobre incorporação realizada & 3 & 1 & 0 & 0 & 3 & 0 \\
\hline 6 & Esclarecimentos sobre demonstrações complementares & 62 & 17 & 16 & 5 & 78 & 11 \\
\hline 7 & Esclarecimento s/amortização/manutenção/reclassificação de ágio & 6 & 2 & 1 & 0 & 7 & 1 \\
\hline 8 & Esclarecimento sobre a não constituição de provisão p/contingência & 3 & 1 & 1 & 0 & 4 & 1 \\
\hline 9 & Ressalva sobre o saldo de credores diversos & 0 & 0 & 0 & 0 & 0 & 0 \\
\hline 10 & Esclarecimentos sobre operações relevantes com controladas & 2 & 1 & 1 & 0 & 3 & 0 \\
\hline 11 & Esclarec. s/restruturação/liquidação societ e efeito nas demonstrações & 2 & 1 & 1 & 0 & 3 & 0 \\
\hline 12 & Esclarecimentos sobre impostos a recuperar & 4 & 1 & 0 & 0 & 4 & 1 \\
\hline 13 & Esclarecim. sobre informações e demonstrações segregadas por atividade & 3 & 1 & 0 & 0 & 3 & 0 \\
\hline 14 & Esclarecim. sobre oper. venda/compra de energia no mercado atacadista & 4 & 1 & 0 & 0 & 4 & 1 \\
\hline 15 & Esclarecimento sobre reposicionamento tarifário pela ANEEL & 8 & 2 & 1 & 0 & 9 & 1 \\
\hline 16 & Esclarecim.s/contratos concessão de geração de energia eletr. expirados & 1 & 0 & 0 & 0 & 1 & 0 \\
\hline 17 & Ressalva sobre o valor do PL & 1 & 0 & 0 & 0 & 1 & 0 \\
\hline 18 & Esclarec. sobre o parecer com ressalva de demonstrações comparativas & 1 & 0 & 0 & 0 & 1 & 0 \\
\hline 19 & Esclarecimentos sobre recebimentos de sinistros & 1 & 0 & 0 & 0 & 1 & 0 \\
\hline 20 & Esclarecimentos sobre ativos regulatórios/descontinuidade de ativos & 3 & 1 & 1 & 0 & 4 & 1 \\
\hline 21 & Esclarec.s/ demonstr. Complem. e parecer de demonstr. comparativas & 2 & 1 & 0 & 0 & 2 & 0 \\
\hline 22 & Ressalva sobre operações imobiliárias & 0 & 0 & 0 & 0 & 0 & 0 \\
\hline 23 & Esclarecimentos sobre reelaboração/ajustes de demonstrações & 5 & 1 & 3 & 1 & 8 & 1 \\
\hline 24 & Esclarecimentos de divergências entre práticas americanas e brasileiras & 1 & 0 & 31 & 9 & 32 & 5 \\
\hline 25 & Inclusão de demonstrações das sociedades de propósitos específicos & 1 & 0 & 0 & 0 & 1 & 0 \\
\hline 26 & Esclarecim. s/negociação c/o Governo de SP p/ressarc.aposent/pensões & 3 & 1 & 1 & 0 & 4 & 1 \\
\hline 27 & Esclarecimentos sobre controles internos da organização & 0 & 0 & 22 & 6 & 22 & 3 \\
\hline 28 & Esclarecimentos sobre as limitações dos controles internos & 0 & 0 & 17 & 5 & 17 & 2 \\
\hline 29 & Esclarecimentos sobre auditoria nas demonstrações consolidadas & 0 & 0 & 7 & 2 & 7 & 1 \\
\hline 30 & Esclarecimentos sobre planos/benefícios de aposentadoria/pensão & 0 & 0 & 14 & 4 & 14 & 2 \\
\hline 31 & Parecer do auditor acerca dos controles internos & 0 & 0 & 27 & 8 & 27 & 4 \\
\hline 32 & Esclarecimentos sobre deficiências nos controles internos & 0 & 0 & 4 & 1 & 4 & 1 \\
\hline 33 & Ressalva sobre os controles internos & 0 & 0 & 2 & 1 & 2 & 0 \\
\hline & Totais & 368 & 100 & 353 & 100 & 721 & 100 \\
\hline
\end{tabular}




\subsection{Características Relativas às Práticas de Auditoria Brasileiras e Norte- Americanas}

A análise do conteúdo dos pareceres da auditoria independente, em relação às demonstrações contábeis elaboradas, tanto de acordo com as práticas contábeis brasileiras como as americanas, observou algumas características, descritas a seguir.

Com relação aos pareceres sobre as demonstrações contábeis divulgadas no mercado acionário americano, algumas empresas de auditoria destacam, em lugar distinto, esclarecimentos sobre as diferenças entre o padrão contábil brasileiro e o padrão contábil americano. Isso foi observado em 31 parágrafos, equivalente a 9\% do total (Tabela 5).

A auditoria divulgada ao mercado acionário americano também dá uma atenção especial aos controles internos das empresas auditadas. Isso pode ser observado em 72 parágrafos (20\% do total). Em alguns casos, há um parecer específico referente ao controle interno; em outros, há um lugar de destaque sobre para a eficácia dos controles internos. Há casos em que a Diretoria Financeira fica responsável por um relatório referente aos controles internos.

Todas as empresas pesquisadas divulgaram no mercado acionário, mesmo sem haver a obrigatoriedade no Brasil, na época da pesquisa, a Demonstração do Fluxo de Caixa (DFC). Algumas também divulgaram a Demonstração do Valor Adicionado (DVA). As empresas de auditoria têm destacado os exames realizados sobre essas demonstrações e emitido um parecer sobre as mesmas, em parágrafo específico, tanto no Brasil como nos EUA.

No Brasil são divulgadas as demonstrações contábeis dos últimos dois exercícios e sobre elas é emitido o parecer da auditoria. Já nos EUA são divulgadas as demonstrações dos últimos três exercícios e os respectivos pareceres.

No Brasil, quando a atual empresa de auditoria não realizou o exame das demonstrações do penúltimo exercício, ela menciona que não é responsável pelo trabalho e pela emissão do parecer daquele ano, podendo apontar, caso exista, algum fato relevante constante naquele parecer.

Nos Estados Unidos, quando não há a coincidência da mesma empresa de auditoria, ela menciona qual(is) o(s) ano(s) que ela foi responsável pelo exame, divulgando o(s) parecer(es) do(s) ano(s) em que a auditoria foi realizada por outra empresa.

As situações relevantes destacadas em parágrafo de ênfase no parecer sobre as demonstrações apresentadas à BOVESPA, também estão destacadas, na maioria das vezes, e em parágrafo próprio, no parecer divulgado na NYSE.

Um fato relevante evidenciado neste estudo é que dos 156 pareceres de auditoria independente analisados, apenas um foi com ressalva, tanto para as demonstrações elaboradas conforme as práticas contábeis adotadas no Brasil como para as elaboradas de acordo com as práticas contábeis norte-americanas e disponibilizadas nos respectivos portais da BOVESPA e NYSE. Isso demonstra o entendimento dado pelas empresas de auditoria de que as demonstrações contábeis auditadas representam, nos seus aspectos relevantes, a realidade da situação patrimonial, econômica e financeira das empresas auditadas.

Quanto aos responsáveis pelos pareceres das demonstrações contábeis divulgadas no site da BOVESPA, das 26 empresas pesquisadas, apenas uma foi auditada, em 2005, por empresa de auditoria diversa da que auditou em 2004. Em 2006, comparativamente a 2005, isso ocorreu em sete empresas. Quanto aos pareceres divulgados no site da NYSE, as demonstrações de 2005 tiveram os mesmos auditores de 2004, contrariamente a 2006, quando ocorreram seis trocas em relação a 2005. Nota-se, portanto, que não houve diferenças significativas entre as mudanças ocorridas nas auditorias feitas no Brasil e nos EUA.

Quanto a esse aspecto, há que se destacar o fato das empresas estarem optando por contratos globais. Dentro dessa estratégia, não há a necessidade de celebrar um contrato com 
outra empresa de auditoria para a realização do trabalho sobre as demonstrações contábeis de acordo com as práticas contábeis brasileiras e norte-americanas. Trata-se, provavelmente, mais de uma prática econômica adotada para a realização de um contrato único de prestação de serviço de auditoria abrangendo a emissão de ambos os pareceres.

Isso pode ser confirmado pelos dados da pesquisa. A análise possibilitou constatar que, na grande maioria das ocorrências, a empresa de auditoria responsável pelo parecer das demonstrações contábeis divulgadas na BOVESPA, elaboradas de acordo com as normas brasileiras de contabilidade, é a mesma que emitiu o parecer das demonstrações divulgadas na NYSE, elaboradas conforme as normas contábeis americanas. Isso ocorreu em 24 das 26 empresas, uma preferência de $92 \%$. As exceções foram o Banco Bradesco e a Tele Norte Leste em 2004 e 2005 e no ano de 2006 as duas empresas a Tele Norte Leste e a Tim.

Não há uma razão aparente para essas exceções, principalmente porque nelas as auditorias sempre foram realizadas por uma das quatro empresas estrangeiras. Ou seja, foi realizado um contrato com uma delas para a realização do trabalho visando o mercado acionário brasileiro e efetivado um outro contrato, com uma outra das quatro empresas de auditoria, para a elaboração do trabalho destinado ao mercado acionário americano.

\section{CONSIDERAÇÕES FINAIS}

Analisados os pareceres emitidos pela auditoria independente acerca das demonstrações contábeis de empresas brasileiras com registro na BOVESPA e na NYSE, relativas ao período de 2004, 2005 e 2006, pode-se concluir que as empresas brasileiras com ações negociadas na BOVESPA e na NYSE estão respeitando, nos seus aspectos relevantes, as normas contábeis brasileiras, nas demonstrações publicadas no Brasil; e as normas contábeis americanas, nas demonstrações publicadas nos Estados Unidos. Essa é uma conclusão geral baseada no fato de que a quase totalidade dos pareceres analisados foram emitidos sem ressalva.

Tem-se que as quatro principais empresas mundiais de auditoria detêm participação majoritária na responsabilidade pela emissão do parecer de auditoria das empresas pesquisadas. Assim, dado que cada vez mais empresas brasileiras têm procurado negociar suas ações na principal bolsa de valores dos Estados Unidos, a tendência é de que as empresas brasileiras de auditoria venham a ter reduzidas suas participações na emissão de parecer sobre as demonstrações contábeis de companhias abertas brasileiras.

Mapeadas as empresas de auditoria independente que auditaram as Demonstrações Contábeis do ano de 2004 a 2006 das empresas brasileiras registradas na BOVESPA e na NYSE, nota-se que, dentre as quatro principais empresas de auditoria, a Deloitte é a que possui a maior quantidade de clientes, dentre as empresas analisadas. E é a única que obteve um acréscimo de clientes em 2006, se comparado à quantidade de clientes que possuía em 2005 e 2004.

Após verificar se as empresas de auditoria foram as mesmas que atuaram nos três exercícios sociais estudados, nota-se que, na grande maioria, as ocorrências foram as mesmas. Além disso, elas são as mesmas tanto para as demonstrações elaboradas sob padrões contábeis brasileiros como sob os padrões americanos, com exceção de duas empresas em 2004, em 2005 e em 2006.

Quanto à análise do tipo de parecer emitido, constatou-se que na amostra estudada foi utilizado, em praticamente $100 \%$ dos casos, o parecer sem ressalva, tanto para as demonstrações brasileiras como para as americanas. Quanto à análise do conteúdo dos pareceres, ficou evidente que os emitidos sobre as demonstrações divulgadas ao mercado americano, comparativamente às brasileiras, dá ênfase maior à eficácia dos controles internos. 
Nota-se que as principais empresas brasileiras buscam fornecer aos acionistas e demais usuários das demonstrações contábeis informações extras, em relação às que eram obrigadas a divulgar, na época, em função da legislação brasileira. Essa conclusão decorre do fato de que todas as empresas analisadas divulgaram a Demonstração do Fluxo de Caixa e, em algumas, também a Demonstração do Valor Adicionado.

Por meio da regressão estatística aplicada aos dados coletados, pode-se afirmar que a apresentação de papéis acionários na NYSE, por empresas brasileiras, tem influência positiva na contratação de auditores internacionais, conforme dado explicado pela probabilidade de 95\%. Infere-se que a economia sem fronteiras tem afetado, também, o mercado de auditoria independente, uma vez que foi detectado que este serviço, nas empresas pesquisadas, está concentrado nas quatro grandes empresas mundiais de auditoria.

No decorrer da pesquisa, detectou-se a necessidade de continuidade da pesquisa visando uma ampliação dos dados analisados, bem como a utilização de outros fatores não considerados nesta regressão. De fato, a internacionalização dos padrões contábeis e de auditoria carece ainda de estudos que viabilizem melhor o entendimento das divergências ainda existentes e caminhos alternativos para a sua redução.

\section{REFERÊNCIAS}

AMERICAN INSTITUTE OF CERTIFIED PUBLIC ACCOUNTANTS (AICPA). Auditing, attestation, and quality control standards. Disponível em: <http://www.aicpa.org/download/auditstd/2004_10_ASB_OPERATING_POLICIES.pdf>. Acesso em: 21 fev. 2009.

ALMEIDA, J.J. Marques. A auditoria legal na União Européia: enquadramento, debate actual e perspectivas futuras. Revista Contabilidade \& Finanças, n. 28, p.29-38, jan-abr 2002.

ALMEIDA, Marcelo Cavalcanti. Auditoria: um curso moderno e completo. 6. ed. São Paulo: Atlas, 2003.

ANTUNES, Jerônimo. Contribuição ao estudo da avaliação de risco e controles internos na auditoria de demonstrações contábeis no Brasil. 1998. Dissertação (Mestrado em Contabilidade e Controladoria) - FEA/USP, São Paulo, 1998.

ANTUNES, Jerônimo. Modelo de avaliação de risco de controle utilizando a lógica nebulosa. 2004. Tese (Doutorado em Contabilidade e Controladoria) - FEA/USP, São Paulo, 2004.

ARAÚJO, Francisco José. Compreensão do parecer do auditor independente no Brasil. Revista Brasileira de Contabilidade, n. 139, p. 71-81, jan./fev.2003.

ATTIE, William. Auditoria: conceitos e aplicações. 3. ed. São Paulo: Atlas, 1998.

Bolsa de Valores de São Paulo (BOVESPA). Companhias listadas. Disponível em: <http://www.bovespa.com.br>. Acesso em: 19 out. 2007.

BRASIL. Lei $\mathbf{n}^{\circ} \mathbf{6 . 3 8 5}$, de 07 de dezembro de 1976. Dispõe sobre o mercado de valores mobiliários e cria a Comissão de Valores Mobiliários.

BRASIL. Lei $\mathbf{n}^{\circ} \mathbf{1 1 . 6 3 8}$, de 28 de dezembro de 2007. Altera e revoga dispositivos da Lei $\mathrm{n}^{\circ}$ 6.404/76 e estende às sociedades de grande porte disposições relativas à elaboração e divulgação de demonstrações contábeis. Brasília, DOU, 28/12/2007 - Edição Extra.

CHURCH, B.K.; DAVIS, S.M.; McCRACKEN, S.A. The auditor's reporting model: a literature overview and research synthesis. Accounting Horizons, v. 22, n. 1, p. 69-90, March 2008. doi:10.2308/acch.2008.22.1.69 
CONSELHO FEDERAL DE CONTABILIDADE (CFC). Resolução CFC no 820, de 17 de dezembro de 1997. Aprova a NBC T 11 - Normas de Auditoria Independente das demonstrações contábeis, com alterações e outras providências.

Resolução CFC no 830, de 11 de dezembro de 1998. Aprova a NBC T 11 - IT 05 Parecer dos Auditores Independentes sobre as Demonstrações Contábeis.

Resolução CFC no 1.024, de 15 de abril de 2005. Aprova a NBC T 11.3 - Papéis de Trabalho e Documentação de Auditoria.

Resolução CFC no 1.035, de 26 de agosto de 2005. Aprova a NBC T 11.4 Planejamento da Auditoria.

Resolução CFC $\mathbf{n}^{\circ} \mathbf{1 . 0 4 0}$, de 26 de agosto de 2005. Aprova a NBC T 11.16 Transações e Eventos Subsequentes.

Comissão de Valores Mobiliários (CVM). Site institucional. Disponível em: <http://www.cvm.gov.br>. Acesso em: 22 out. 2007.

DAVIS, Robert R. Using disclaimers in audit reports. The CPA Journal, v. 74, n. 4, p. 2629. Apr. 2004.

DIXON, Robert; MOUSA, Gehan A.; WOODHEAD, Anne D. The necessary characteristics of environmental auditors: a review of the contribution of the financial auditing profession. Accounting Forum, v. 28, n. 2, p. 119-138, Jun. 2004. doi:10.1016/j.accfor.2004.01.001

DUTRA, Marcelo Haendchen; ALBERTON, Luiz; VAN BELLEN, Hans Michael. A análise de conteúdo aplicada aos parágrafos de 'ênfase' e de 'informação relevante' dos pareceres da auditoria independente emitidos para as empresas do Setor Elétrico. In: ENANPAD, 2007, Rio de Janeiro. Anais ... Rio de Janeiro: ANPAD, 2007

ELAHEE, M.N.; PETRIE, A.G.; GANGULI, G. Comparison of US and UK auditing standards. International Advances in Economic Research, v. 3, n. 3, p. 328-329, Aug. 1997. doi:10.1007/BF02294928

Financial Accounting Standards Board (FASB). Elements of financial statements. Disponível em: 〈www.fasb.org>. Acesso em: 27 nov. 2007.

FRANCO, Hilário; MARRA, Ernesto. Auditoria contábil. 3. ed. São Paulo: Atlas, 2000.

GIL, Antonio Carlos. Como elaborar projetos de pesquisa. 4. ed. São Paulo: Atlas, 2002.

HILL, R. Carter; GRIFFITHS, William E.; JUDGE, George G. Econometria. 2. ed. São Paulo: Saraiva, 2003.

INTERNATIONAL FEDERATION Of ACCOUNTANTS (IFAC). Normas Internacionales de Auditoria: emitidas por el comité internacional de prácticas de auditoria, IMCP, 3. ed., 1997.

INTERNATIONAL AUDITING AND ASSURANCE STANDARDS BOARD (IAASB). Planning an audit of financial statements. Disponível em: www.ifac.org/IAASB/ProjectHistory.php?Proj/D=0017. Jun, 2004. Acesso em: 15 out. 2007.

MARCONI, Marina de Andrade; LAKATOS, Eva Maria. Fundamentos de metodologia científica. 6. ed. São Paulo: Atlas, 2006.

MARTINS, Gilberto de Andrade. Manual para elaboração de monografias e dissertações. 3. ed. São Paulo: Atlas, 2002. 
NEW YORK STOCK EXCHANGE (NYSE). Listed company directory. Disponível em: <http://www.nyse.com/about/listed/listed.html> Acesso em: 15 out. 2007.

PUBLIC COMPANY ACCOUNTING OVERSIGHT BOARD (PCAOB). About the PCAOB. Disponível em: www.pcaobus.org. Acesso em: 21 fev. 2009.

RAUPP, Fabiano Maury; BEUREN, Ilse Maria. Metodologia da pesquisa aplicável às ciências sociais. In: BEUREN, Ilse Maria (org.). Como elaborar trabalhos monográficos em contabilidade: teoria e prática. 2. ed. São Paulo: Atlas, 2004.

ROUSSEY, S. Robert. New focus for the international standards on auditing. Journal of International Accounting, Auditing and Taxation, v. 5, n. 1, p. 133-146, 1996. doi:10.1016/S1061-9518(96)90019-1

SÁ, Antônio Lopes. Curso de auditoria. 9. ed. São Paulo: Atlas, 2000.

SILVA, Antonio Carlos Ribeiro. Metodologia da pesquisa aplicada à contabilidade. São Paulo: Atlas, 2003.

SMITH, Murphy; SAGAFI-NEJAD, Tagi; WANG, Kun. Going international accounting and auditing standards. Internal Auditing, v. 23, n. 4, p. 3-12, Jul., 2008.

WEINSTEIN, Edward. Materiality: whose business is it? The CPA Journal, v. 77, n. 8, p. 24-29, Aug. 2007.

WHITTINGTON, R.; GRAHAM, L.; DISCHBACH, G.; AHERN, J. Advancing the audit documentation standard. Journal of Accountancy, v. 201, n. 6, p. 64-69, Jun. 2006.

WOOLDRIDGE, Jeffrey M. Introdução à econometria: uma abordagem moderna. São Paulo: Pioneira Thomson Learning, 2006.

WORTMANN, Richard E. Accounting \& assurance. CPA Journal, v. 80, n. 1, p. 6-8, Spring 2009. 